\title{
Diagnostic and Management in Vesicovaginal Fistulas
}

\author{
Nicolae Bacalbașa ${ }^{1}$, Beatrice Lintoiu², Irina Bãlescu ${ }^{3}$, Mihai Dimitriu ${ }^{4}$
}

${ }^{1}$ Carol Davila University of Medicine and Pharmacy, Bucharest, Romania

${ }^{2}$ Profesor Dr. Agripa Ionescu Clinical Emergency Hospital, Bucharest, Romania

${ }^{3}$ Ponderas Hospital, Bucharest, Romania

${ }^{4}$ St. Pantelimon Clinical Emergency Hospital, Bucharest, Romania
Corresponding author:

Nicolae Bacalbașa, MD

Dimitrie Racoviță Street, no. 2,

Bucharest, Romania

E-mail: nicolae_bacalbasa@yahoo.ro

\section{ABSTRACT}

Vesicovaginal fistulas are among the most distressing complications of gynecologic and obstetric procedures. The risk of developing vesicovaginal fistula is more than $1 \%$ after radical surgery and radiotherapy for gynecologic malignancies. Management of these fistulas has been better defined and standardized over the last decade. The discussions concerning fistula repair has evolved from transabdominal/transvaginal approach to minimally invasive surgeries.

Key words: vesicovaginal fistula, female urogenital diseases, gynecologic surgical procedures

\section{INTRODUCTION}

A vesicovaginal fistula (VVF) is a debilitating condition that has affected women for millennia.

There is reference to this condition in the Ebers papyrus dating from $1550 \mathrm{BC}$ and in Cairo School of Medicine was identified a large vesicovaginal fistula in the mummy of a woman from the court of king Mentuhotep II of Egypt of the eleventh dynasty who reigned around 2050 BC (1). The first literary mention of this type of fistula is found in Al-Kanoun written by the Persian physician Ibn-Sina (Avicenna). In his medical text book written around 950 AD he documented the relationship between VVF and obstructed labour, or traumatic delivery - "the bulk of the fetus may cause a tear in the bladder which results in incontinence of urine which is incurable and remains so untill death" (2).

The first reference to fistula surgery in the European literature came from Hendrick Van Roonhuise in 1663. He described the use of the lithotomy position, good exposure of the fistula using a speculum, marginal denudation of the bladder wall and approximation of the denudated edges with silk. In 1779 Mittchel reported spontaneous healing of an obstetric fistula aided by continuous catheter drainage (3). In 1845, a series of experimental operations on slaves was conducted in Montgomery, Alabama, USA and based on these experiments, James Marion Sims established the foundations of VVF repair in 1852: proper exposure with the knee-chest position; the use of a vaginal retrac- 
tor; the use of silver-wire sutures; tension-free closure of the defect; proper postoperative bladder drainage (4).

\section{ETIOLOGY}

VVFs are epithelialised or fibrous communications between the bladder and vagina, a relatively uncommon pathology, with an etiology that varies geographically. In developed countries, the true incidence of VVF is unknown, but it is estimated at $0.3-2 \%$. It is secondary to benign gynaecological surgery in $80 \%$, to obstetric trauma in $10 \%$, to radiotherapy in $5 \%$ and to gynaecological oncological procedures in $5 \%$ of the cases (5).

Conversely, in developing countries, VVF is most commonly related to childbirth (6).

In countries such as Nigeria, the WHO estimated that 800000 - 1 million women had an unrepaired VVF in 2001. So, prolonged or obstructed labour is the most prevalent cause of VVF in the developing countries (97\%)(4). Pelvic tumours and trauma, congenital anomalies, foreign body and abscess account for less than $5 \%(4,7,8)$.

latrogenic (after surgery) vesicovaginal fistula - 81 $91 \%$ of VVF in developed countries occur during the healing process after pelvic surgeryor pelvic irradiation. Direct laceration or puncture injury to the urinary tract result in immediate urine leakage. Delayed injury from retroperitoneal fibrosis, tissue pressure or partial obstruction might manifest as fistula formation and urine leakage after many days or even weeks (9).

In developed countries, hysterectomyis the most common surgical procedure resulting in VVF formation, usually above the trigone, at the level of the vaginal cuff. The incidence varies depending on the approach - the lowest is with transvaginal (0.2:1000), followed by transabdominal (1:1000) and laparoscopic procedures (2.2:1000)(4).

In the United States, the majority of vesicovaginal fistulas arise most frequently after a total abdominal hysterectomy (6). In the series by Lee et al (10), $90 \%$ of the vesicovaginal fistulas encountered were the result of surgical treatment for a 'benign' condition, with total abdominal hysterectomy accounting for $70 \%$ of the fistulas. In the surgical treatment of cancer, there is a higher risk of urologic complications, with a $1 \%$ risk for ureteral and vesical injuries associated with radical hysterectomy for cervical cancer. Post-operative fistulas are usually an early complication, appearing approximately 10 days after hysterectomy, while radiation induced fistulas may occur many years after treatment. Even though numerous predisposing factors in the development of the postoperative fistula have been identified (infection, ischemia, arteriosclerosis, previous uterine surgery, cancer treatments and diabetes), the vast majority occur under "very normal operative circumstances". In cases associated with gynecologic cancers, the management of vesicovaginal fistula presents unique difficulties and the fistula can be a result of a surgical complication, radiation treatment or due to the presence of cancer (6).

Radiotherapy, used therapeutically or as an adjuvant, increases the risk of VVF. It decreases the vascularity of tissue, rendering it friable and impairing healing. Therapeutic radiotherapy causes obliterative endo arteritis which progresses over the years and cause the late presentations of some fistulas and also makes the repair the fistula less successful because of poor healing $(4,11)$.

Non-iatrogenic (obstetric) vesicovaginal fistula obstetric trauma is primarily responsible for the $98 \%$ of the urogenital fistula in sub-Saharan African countries such as Nigeria. This is primarily due to the shortage of medical care, with one physician serving up to 200000 individuals (11). In Western countries, obstructed labour represents only $5 \%$ of all VVFs (4).

Fistulas complicating the treatment of gynecologic malignancies are a rare occurrence. In Emmert's series (12) of patients treated for cervical cancer, only $0.42 \%$ developed vesicovaginal fistulas. All these patients had received radiation therapy in addition to other treatments.

\section{DIAGNOSIS}

Classically, fistulas occur between the $7^{\text {th }}$ and the $12^{\text {th }}$ day after surgery, ranging from immediate to 6 weeks. Radiation induced fistulas develop and are recognized later when compared with postoperative fistulas, even 20-30 years after the end of treatment (4).

A high index of suspicion remains the most important diagnostic tool for VVF. The review of the patient's medical and surgical history and a careful physical examination are very important for the diagnosis.

The classical presentation sign is continuous (day and night) incontinence after a recent pelvic operation. If the fistula is small, watery discharge from the vagina accompanied by normal voiding may be the only symptom. An intermittent leakage of urine from the vagina can be a sign of a ureterovaginal fistula. Bleeding and localized pain may also be present. Intra-abdominal urinary extravasation can present with abdominal pain and ileus. Potential secondary effects to vaginal urinary discharge include vulvar irritation, recurrent infections 
or pyelonephritis leading to renal insufficiency $(4,6)$.

On vaginal examination, the VVF can appear as a small, red granulated area with no visible opening. Small fistulas can be located by instilling methylene blue through a Foley catheter into the bladder. If no defect is clearly seen, cystoscopy can be a valuable diagnostic tool. In addition to the cystoscopy and the cistourography, an intravenous pyelo ureterogram is recommended to rule out concomitant ureteral fistulas before proceeding with the surgical repair. Goodwin et al. (13) found that $12 \%$ of patients with a vesicovaginal fistula had a concomitant ureterovaginal fistula. Fluorourodynamic studies are used to determine bladder compliance, capacity and outlet competence and to identify hidden fistulas (4).

Imaging plays a complementary role in helping to identify the presence and site of a fistula and is essential for establishing its course and complexity magnetic resonance imaging (MRI) and computer tomography (CT) are currently the imaging modalities of choice for the evaluation of patients in whom the presence of apelvic fistula is suspected. In patients with gynecologic malignancies in whom the presence of a fistula is suspected, MRI has the added advantage of depicting a recurrence, radiation therapy - related fibrosis or adhesions within the pelvis, all of which have important implications for surgical management. Three-dimensional CT reconstructions of complex vesicovaginal fistulas help identify the precise course of the fistulous tract and provide the detailed anatomic views the surgeon needs for preoperative planning $(4,6,10)$.

\section{FISTULA CLASSIFICATION}

Vesicovaginal fistulas can be classified in various ways. Simple fistulas are considered the ones with small size $(\leq 0.5 \mathrm{~cm})$ and present as single non-radiated fistulas. Complex fistulas include large $(>2.5 \mathrm{~cm})$ fistulas, previously failed fistula repairs or due to chronic diseases or radiotherapy. Fistulas that develop in radiated tissue are often multiple and difficult to treat. Most authors consider intermediate size fistulas (0.5 $2.5 \mathrm{~cm}$ ) as complex (6).

A surgical grading system was described for obstetric fistulas (14) with type I fistulas not involving the urethral-closing mechanism, type II fistulas involving the urethral-closing mechanism and type III fistulas involving the ureter and other exceptional fistulas.

\section{PREVENTION}

For iatrogenic fistulas, good surgical techniques should always be used to decrease the ocurrence of injury. The surgeon should take extra care to notice and manage such injuries during surgery, if they occur. However, fistula can still form despite the recognition and repair of an injury. For some fistulas, such as the ones related to radiotherapy, it might be impossible to prevent since tissue devascularisation causes delayed injury. In developing countries, better access to obstetric care and drainage of the bladder during labour are useful preventive measures.

\section{MANAGEMENT}

\section{Conservative treatment}

In $10 \%$ of cases the fistula closes spontaneously after 0.5-2 months of urethral catheterization, especially if the fistula is small $(<0.5 \mathrm{~cm})$, detected early or there is no epithelialization of the fistula. If the diagnosis is late and the fistula has epithelialized, electrocoagulation of the mucosal layer and 2-4 weeks catheterization may lead to closure. Anticholinergic drugs may be used to relax the detrusor muscle, preventing spasm and topical estrogens can be used in postmenopausal women to promote healing. Conservative treatments have varying degrees of success, depending on the cause, size and location of the fistula, butin most cases these conservative methods fail $(5,9,15,16)$.

\section{Surgical repair}

The most important therapeutic decisions are when to perform the repair and the type of the procedure. Initial repair is critical since it is usually the most likely to succeed. Healthy tissue allows an early repair, but unhealthy tissue (inflammation, infection, or tissue necrosis) needs a 2-3 month delay in order to obtain a successful repair.

The traditional approach in the treatment of VVF is to delay surgery thus allowing the tissues to revascularize. However, recent studies show that in iatrogenic fistula there is no benefit in delaying surgery, as the tissues are not indurated. The results for immediate repair are comparable with the ones from previous reports favouring delayed repair $(17,18)$. The advantage of an early repair is an immediate improvement in the quality of life. This is whyin an uncomplicated VVF after hysterectomy excising and repairing a fistulous tract at 1-2 weeks after confirmation of leakage has become increasingly more common (19). Zimmern et al. (20) did not find increased morbidity or failure after the early repair of a VVF at 2-3 weeks after injury. Waaldijk (21) 
also concluded that the immediate management of obstetric fistulas was highly effective in terms of closure and continence, thus preventing the medically, socially and mentally downgrading of the patient.

Radiotherapy - related fistulas need time for adequate tissue regeneration before attempting a repair. In this case it is acceptable to delay the repair for a 3-6 month period.

The timing of intervention should aim to find the compromise between the desire to free the patient from urinary loss and to wait for the optimal conditions for closure.

The best timing in general is when there is no edema, inflammation or any infection, but "the timing and route of surgical repair are best tailored to the individual" $(4,5,10,15)$.

Some steps in the repair of a VVF are basic to achieve successful repair: mobilization of tissues, proper identification and excision of the damaged tissues, closure without tension.

The choice of surgical repair depends on the type and location of the fistula, the surgeon's experience and the patient's specific preferences. In general, simple fistulas are treated using vaginal approaches, while complex fistulas are treated either vaginally or transabdominally.

The current trend towards a transvaginal approach, even for deep and large fistulas, has been associated with lower morbidity rates than transabdominal repairs, with a similar good outcome.

\section{The transvaginal approach}

Regardless of the etiology of the fistula, the vaginal approach is the preferred one. Contraindications to vaginal approach include: severely indurated vaginal epithelium around the fistula, small capacity or poorly compliant bladder, vaginal stenosis, repair requiring ureteral reimplantation, involvement of other pelvic structures (22).

Woo et al. concluded that most fistulas can be closed transvaginally, but abdominal access is recommended if the fistula is high in a narrow vagina and close to the ureteric orifices (6).

Although the first successful closures were based on excising the fistula, thus providing fresh edges for optimal wound healing, there is a risk of conversion of a small tract into a larger one, and also the risk of bleeding.

The two most commonly techniques are the Latzko technique and the layered closure. These approaches can be performed with or without a fat pad or myocutaneous flap $(4,17)$.

\section{The Latzko procedure}

The Latzko procedure is an excellent vaginal technique used by many surgeons. It consists in denudement of the vaginal wall for approximately $1 \mathrm{~cm}$ around the fistula, without excising the fistulous tract at the level of the bladder, with a layered imbricating closure of the bladder, vesicovaginal fascia and vagina separately. The advantages of this approach include minimal blood loss, simplicity of the technique and low risk of ureters and urethra injury since the bladder is not opened $(6,10,17)$. Tancer et al. (23) reported a success rate of $93 \%$ with this technique and did not find the shortening of the vagina to be a problem, as was described by some authors. The Latzko procedure has even been successfully utilized in patients with recurrent fistulas who already had undergone a primary Latzko procedure (6).

\section{Layered closure}

Layered closure technique is used to correct simple, small fistulas. The excision of the fistula is performed after separating the bladder from the vaginal mucosa and the underlying fascia for approximately $1.5 \mathrm{~cm}$. The full thickness of the fistula is excised and the bladder closed in two layers. The first layer is extramucosal and the second imbricates the first one. The last layer is the closure of the vaginal wall. The main difference between the Latzko and the layered closure consists in the excision of the vesical mucosa during the layered closure $(1,6)$.

\section{Martius flap}

In general, the Martius flap is used as treatment for complex fistulas, including recurrent, radiation induced or large fistulas. The procedure involves the use of a $5-6 \mathrm{~cm}$ long and $2-3 \mathrm{~cm}$ wide fat pad along the length of the labium majus which is elevated and tunneled subcutaneously into the vagina to act as an inter-positional vascular flap.

This flap is classically developed by making a vertical incision along the external surface or the medial border of the labia majora. It is supplied by the perineal branch of the internal pudendal and the external pudendal artery and collaterals. When the fistula is complex and there is a significant deficit of blood supply, the bulbocavernosus muscle (modified Martius flap) can also be utilized, along with the subcutaneous and cutaneous tissue (myocutaneous flap). The flap can be uni- or bilateral according to the anatomical characteristics of the fistula $(3,4,13,24)$. 


\section{The transabdominal approach}

A wide dissection of the bladder and vagina is fundamental and the vaginaland bladder suture lines should be placed far apart. The aims of any procedure are a closureand separation of the two epithelial layers of the bladder and vaginal wall.

The abdominal approach can be performed using a transvesical (fistula excision) or an extravesical (bivalve technique) approach, but in reality both procedures involve the opening of the bladder $(4,6,17)$.

\section{Bivalve technique}

Bivalve technique is performed by mobilizing the bladder before incising it. The vertical incision is carried from the dome to the fistulous tract, which is excised. The bladder is mobilized from the vagina, with direct visualization and resection of the defect and easy placement of ureteral catheters, if fistula repair involve the trigone. The vaginal wall has to be repaired separately from the bladder and a two-layer closure must be performed, first closing the vagina then the bladder. This approach also allows the interpositional of an omental J flap or a peritoneal flap between the bladder and the vagina in cases with poor tissue viability (scar tissue, radiation fibrosis) (25). The goal of this type of repair (with flap) is to provide a new blood supply to damaged, devascularized tissue around the fistula by inserting healthy tissue.

The O'Conor approach, with a success rate of 85$100 \%$, provides excellent mobilisation of different layers and omental interposition. This technique involves midline bivalving of the bladder, passing and then excising the fistula. The bladder (two to three layers) and vagina (two layers) are then closed. Omental interposition is routinely used (8).

\section{Transvesical repair}

Transvesical repair is an abdominal approach performed by opening the bladder at the level of the dome, so that the fistulas can be visualized and then excised. The bladder is dissected from the vagina transvesically, only around the fistulous tract. The bladder around the fistulous tract excised is then closed perpendicularly to the closure of the vagina. The advantage of this technique is the limited vesicovaginal dissection. Disadvantages consist of limited exposure and the inability of using aninterpositional flap between the bladder and the vagina because the vesicovaginal space has not been developed (26).

\section{Urinary diversion}

Repair of radiation induced vesicovaginal fistula or multiple fistulas is often difficult, especially when the anatomy is distorted and the tissue is fibrotic. The success rate in these conditions is poor, and in some occasions, an urinary diversion, such as ileal conduit is indicated.

Radiotherapy - related fistulas are often complex and an abdominal approach is preferableas they are often high fistulas. The use of an omental flap is essential as the tissues are often poorly vascularized. Patients must be made aware of the high risk of failure caused by poor tissue healing and given the option of urinary diversion (27).

In cases of fistulas secondary to recurrentdisease, pelvic exenteration may be warrantedas a salvage procedure, provided that there is noinvolvement of the pelvic side wall or evidence ofdistant disease (28).

In sexually active patients the preservation of vaginaldepth is mandatory for ensuring satisfactory sexualfunction. If the fistula is large or there is postradiation stenosis, sufficient vaginal depth can be achieved by using rotational flaps. However, if the patient is not sexually active, a partial colpocleisis can be used tomaximize tissue coverage (17).

In limited case series laparoscopic repair was reported to be effective in managing VVF (29). This approach is safe and provides all the advantages of minimally invasive surgery, including a shorter hospital stay and recovery time. In 2005, Chibber et al. (8) described a laparoscopic approach of the O'Conor technique. Success rates were reported as high as $93 \%$ at 26 months. Abdel-Karim et al. (30) studied the laparoscopic transperitoneal extravesical repair of a supratrigonal VVF in 15 patients and at mean follow-up of 18.9 months, all patients were cured with no complications during or after surgery.

The laparoscopic repair of a VVF with robotic reconstruction is the most recent technology used in the treatment of VVF. Melamud et al. (31) were among the first to report the robotic reconstruction of a VVF using the DaVinci system. The 16-week follow- up confirmed the cure of a post-hysterectomy proximal VVF. Other authors have also reported excellent outcomes (32). Despite the good results, robotic repair will need further evaluation especially since it involves an increased learning curve, time and cost.

\section{Postoperative care}

Postoperative care is as crucial for a successful repair 
as the procedure itself.

After surgery patients are left with a urethral and/or suprapubic catheter in situ for 4-6 weeks to allow adequate healing. Hydration, a high-volume bladder flow, drains and catheters will ensure constant fluid flow through the bladder. This will help to prevent any catheter blockage due to blood clots, which causes bladder distension and disruption of the repair. Patients with a fistula at the bladder neck or trigone should not be left with a urethral catheter because of the risk of pressure on the repair.

At 10-14 days after surgery a cystogram is performed to ensure that there is no leak before removing the catheter. If there is a persistent leak the catheter is left for 6 weeks to encourage healing and the cystogram repeated. After removing the catheter, the bladder capacity will be reduced by prolonged drainage and the patients are encouraged to void hourly to avoid overdistension of the bladder and compromise of the repair. They can resume a normal voiding pattern by one month. Tampons, douches and sexual intercourse are tobe avoided for 3 months (33).

Prophylactic antibiotics to prevent urinary tract infections can be useful, depending on the duration of catheter drainage. Anticholinergics are used to prevent early suture tension as a result of bladder spasm $(4,33)$.

Specific complications after repair of a fistula include ureteric injury, especially if the fistula is close to the ureteric orifices. This can be minimized by placing ureteric stents during surgery. Patients may develop stress incontinence, although the results of recent studies using urodynamics tests suggest this may be present before the repair is undertaken. Vaginal stenosis resulting in dyspareunia may also be a rare complication $(34,35)$.

Failed repairs require a complete bladder, ureter and kidney evaluation before planning subsequent surgery. The repair often fails in the form of a 'pinpoint fistula' seen at the lateral corners of the previous repair. Repeated repairs will often require the use of softtissue grafts.

Even in a specialised centers these repairs can have a $10 \%$ failure rate. In the event of a failed repair further surgery is possible but the chance of success is diminished to $60 \%$ (34-36).

\section{RESULTS}

The mean success rate of vesicovaginal fistula repair described in the literature, independent of the access route and tissue conditions, approaches $90 \%$ and varies between 40 and $100 \%$ (6).

The success rate of unradiated vesicovaginal fistula repair varies between 70 and $100 \%$ with a mean success rate of $92 \%$. The two approaches, vaginal and abdominal, have similar mean success rates. Most of the vesicovaginal fistulas are repaired vaginally and even a repeat Latzko procedure after a failed Latzko procedure has a chance of success up to $100 \%$ (37).

In recurrent giant fistula, the success rate is low if a single stage procedure is used as compared with twostage repair (12-29 vs. $100 \%$, respectively) as described by lloabachie (38). The two-stage repair, with an interval of 3 months between the procedures, gives to the repaired tissue the time necessary to heal and it is indicated in case of giant fistulas with scanty tissue to cover the defect, especially if fibrosis is significant and involvement of urethrovesical junction is present. In the two staged operation the dissection stop short of the juxta cervical aspect of the fistula in the first stage and thus, the second step is basically a repair of a smaller size fistula.

The success rate of radiation-induced vesicovaginal fistula repairs is between 40 and $100 \%$. Only few case series with limited number of cases have been reported in the literature. Most of the authors prefer an urinary diversion instead of the repair of a radiated fistula, because the surgical procedures are usually complex. For patients undergoing fistula repair, the approach can be either vaginal of transabdominal but in both cases flaps are involved to bring healthy tissue to the affected area. The flap can be simple, such as a bulbocavernosus flap (modified Martius flap) with a $50 \%$ chance for success or more complex such as rectus abdominis flap with a success rate up to $100 \%(5,11,39,40)$.

\section{CONCLUSIONS}

A thorough evaluation of a VVF is of utmost importance when planning a repair. Although the surgeon's experience influences the surgical approach in most cases, some special situations dictate the best approach.

Although simple fistula can be closed by either approach, the vaginal is easier, safer and more comfortable. Adjuvant techniques are needed for complex fistula. The principles of vesicovaginal fistula repair include: adequate exposure of the fistula tract; well-vascularized tissue used for the repair; multiple layer closure; tension-free, non-overlapping suture lines and adequate urinary drainage early after the repair. 


\section{REFERENCES}

1. Riley VJ. Vesicovaginal fistula. EMed WebMD 2006, June 25

2. Ghoniem GM, Khater UM. Vesicovaginal fistula. Pelvic floor dysfunction. London: Springer-Verlag; 2006

3. Rizvi JH. Genital fistulae. A continuing tragedy. J Obstet Gynaecol Res. 1999 Feb;25(1):1-7.

4. Ghoniem GM, Warda HA. The management of genitourinary fistula in the third millennium. Arab J Urol. 2014 Jun;12(2):97-105.

5. Eilber KS, Kavaler E, Rodriguez LV, Rosenblum N, Raz S. Ten-year experience with transvaginalvesicovaginal fistula repair using tissue interposition. J Urol. 2003 Mar;169(3):1033-1036.

6. Angioli R, Penalver M, Muzii L, Mendez L, Mirhashemi R, Bellati F et al. Guidelines of how to manage vesicovaginal fistula. Crit Rev Oncol Hematol. 2003 Dec;48(3):295-304.

7. Harkki-Siren $P$, Sjoberg J, Tiitinen A. Urinary tract injuries after hysterectomy. Obstet Gynecol. 1998 Jul;92(1):113-118.

8. Chibber PJ, Shah HN, Jain P. Laparoscopic O'Conor's repair for vesico-vaginal and vesico-uterine fistulae. BJU Int. 2005 Jul;96(1): 183-186.

9. Symmonds RE. Ureteral injuries associated with gynecologic surgery: prevention and management. Clin Obstet Gynecol. 1976 Sep;19(3): 623-644.

10. Lee RA, Symmonds RE, Williams TJ. Current status of genitourinary fistula. Obstet Gynecol. 1988 Sep;72(3 Pt 1):313-319.

11. Zoubek J, McGuire EJ, Noll F, DeLancey JO. The late occurrence of urinary tract damage in patients successfully treated by radiotherapy for cervical carcinoma. J Urol. 1989 Jun;141(6):1347-1349.

12. Emmert C, Kohler U. Management of genital fistulas in patients with cervical cancer. Arch Gynecol Obstet. 1996;259(1):19-24.

13. Goodwin WE, Scardino PT. Vesicovaginal and ureterovaginal fistulas: a summary of 25 years of experience. J Urol. 1980 Mar;123(3):370374.

14. Waaldijk K. Surgical classification of obstetric fistulas. Int J Gynaecol Obstet. 1995 May;49(2):161-163.

15. Kursh ED. Etiology, evaluation, and endoscopic management of vesicovaginal fistulas. In: Kursh ED, McGuire EJ, editors. Female urology. Philadelphia: J.B. Lippincott; 1994. p. 359.

16. Latzko W. Postoperative vesicovaginal fistulas. Genesis and therapy. Am J Surg 1992;48:211.

17. Thomas K,Williams G. Medicolegal aspects of vesicovaginal fistulae. BJU Int. 2000 Aug;86(3):354-359.

18. Blandy JP, Badenoch DF, Fowler CG, Jenkins BJ, Thomas NW. Early repair of iatrogenic injury to the ureter or bladder after gynecological surgery. J Urol. 1991 Sep;146(3):761-765

19. Collins CG, Pent D, Jones FB. Results of early repair of vesicovaginal fistula with preliminary cortisone treatment. Am J Obstet Gynecol. 1960 Nov;80:1005-1012.

20. Zimmern PE, Hadley HR, Staskin DR, Raz S. Genitourinary fistulae Vaginal approach for repair of vesicovaginal fistulae. Urol Clin North Am. 1985 May;12(2):361-367.

21. Waaldijk K. The immediate surgical management of fresh obstetric fistulas with catheter and/or early closure. Int J Gynaecol Obstet. 1994 Apr;45(1):11-16.

22. Blaivas JG, Heritz DM, Romanzi LJ. Early versus late repair of vesicovaginal fistulas: vaginal and abdominal approaches. J Urol. $1995 \mathrm{Apr}$; 153(4):1110-1112.

23. Tancer ML. The post-total hysterectomy (vault) vesicovaginal fistula. J Urol. 1980 Jun;123(6):839-840.

24. Martius H. Die operative Widerhrstellung dervollkommen fehlenden harnröhre und des Schiessmuskels derselben. Zentralbl Gynak 1928; 52:480-486.

25. O'Conor VJ, Jr., Sokol JK, Bulkley GJ, Nanninga JB. Suprapubic closure of vesicovaginal fistula. J Urol. 1973 Jan;109(1):51-54.

26. Motiwala HG, Amlani JC, Desai KD, Shah KN, Patel PC. Transvesical vesicovaginal fistula repair: a revival. Eur Urol. 1991;19(1):24-28.

27. Penalver M, Angioli R. Urinary diversion. Chapter 11. In: Glenn Hurt W, editor. Urogynecologic surgery. second ed. Lippincot-Raven Press; 2000. p. 193-206.

28. Berek JS, Howe C, Lagasse LD, Hacker NF. Pelvic exenteration for recurrent gynecologic malignancy: survival and morbidity analysis of the 45-year experience at UCLA. Gynecol Oncol. 2005 Oct;99(1):153159.

29. Gozen AS, Teber D, Canda AE, Rassweiler J. Transperitoneal laparoscopic repair of iatrogenic vesicovaginal fistulas: Heilbronn experience and review of the literature. J Endourol. 2009 Mar;23(3):475-479.

30. Abdel-Karim AM, Mousa A, Hasouna M, Elsalmy S. Laparoscopic transperitoneal extravesical repair of vesicovaginal fistula. Int Urogynecol J. 2011 Jun;22(6):693-697.

31. Melamud O, Eichel L, Turbow B, Shanberg A. Laparoscopic vesicovaginal fistula repair with robotic reconstruction. Urology. 2005 Jan; 65(1):163-166.

32. Gupta NP, Mishra S, Hemal AK, Mishra A, Seth A, Dogra PN. Comparative analysis of outcome between open and robotic surgical repair of recurrent supra-trigonalvesico-vaginal fistula. J Endourol. 2010 Nov;24(11):1779-1782.

33. Shaw RW, Soutter WP, Stanton SL, eds. Fistulae. In Gynaecology. 2nd edn. Edinburgh: Harcourt Publishers; 1997.

34. Hilton P. Urodynamic findings in patients with urogenital fistulae. $\mathrm{Br} \mathrm{J}$ Urol. 1998 Apr;81(4):539-542.

35. Schleicher DJ, Ojengbede OHA, Elkins TE. Urological evaluation after closure of vesico-vaginal fistulas. Int Urogynaecol J 1993; 4: 262-265.

36. Hilton P, Ward A. Epidemiological and surgical aspects of urogenital fistulae: a review of 25 years' experience in Nigeria. Int Urogynaecol J 1995; 6: 243.

37. Tancer ML. Observations on prevention and management of vesicovaginal fistula after total hysterectomy. Surg Gynecol Obstet. 1992 Dec;175(6):501-506.

38. Iloabachie GC. Two-stage repair of giant vesico-vaginal fistula. Int J Gynaecol Obstet. 1989 Jan;28(1):27-31.

39. Boronow RC. Repair of the radiation-induced vaginal fistula utilizing the Martius technique. World J Surg. 1986 Apr;10(2):237-248.

40. Viennas LK, Alonso AM, Salama V. Repair of radiation-induced vesicovaginal fistula with a rectus abdominismyocutaneous flap. Plast Reconstr Surg. 1995 Nov;96(6):1435-1437. 